\title{
CRÍTICA DE LA LEGITIMIDAD DEL DERECHO EN TIEMPOS DE EXCLUSIÓN SOCIAL. REPENSAR LA RESPONSABILIDAD DEL ESTADO DESDE EL VÍNCULO SOCIAL DE LA CIUDADANÍA*
}

\author{
CRITICISM OF T HE LEGITIMACY OF LAW IN TIMES OF SOCIAL \\ EXCLUSION. RETHINKING THE RESPONSABILITY OF THE STATE \\ FROM THE SOCIAL BOND OF CITIZENSHIP
}

ASIER MARTÍNEZ DE BRINGAS Universidad de Deusto

Fecha de recepción: 9-10-19

Fecha de aceptación: 4-3-20

Resumen: Este ensayo realizará un análisis de las características estructurales que definen la sociedad de la Modernidad tardía, para entender como estos cambios en la configuración social determinan la manera de entender la política criminal y el Derecho penal frente a los procesos de exclusión. Analizaremos cómo en un contexto de profunda exclusión para determinadas personas y colectivos se desquebraja el necesario vínculo que tiene que darse entre Estado de Derecho y ciudadanía con derechos, fractura, que en la medida que es coadyuvada por el Estado en la producción de las condiciones materiales de exclusión, pondrían poner en tela de juicio la legitimidad de un Estado para castigar al excluido. Para entender todo ello, daremos medida de cuáles podrían ser las condiciones para la configuración de un Estado decente que no humille a sus ciudadanos.

Abstract: This essay will carry out an analysis of the structural characteristics that define the society of late Modernity, to understand how these changes in the social configuration determine the way of understanding criminal policy and Criminal Law in the face of exclusion processes. We will analyze how, in a context of deep exclusion for certain people and groups, the necessary link between the rule of law and citizenship with rights is broken, which, to the

* Este trabajo ha sido realizado en el marco del grupo de investigación interdisciplinar "Derechos humanos y retos socio-culturales en un mundo en transformación" (IT1224-19) del Gobierno Vasco, proyecto adscrito al Instituto de Derechos Humanos de la Universidad de Deusto.

ISSN: 1133-0937

DOI: https://doi.org/10.20318/dyl.2021.5851
DERECHOS Y LIBERTADES

Número 44, Época II, enero 2021, pp. 101-135 
extent that is contributed by the State in the production of material conditions of exclusion, they would call into question the legitimacy of a State to punish the excluded. To understand all this, we will measure what the conditions for the configuration of a decent State that does not humiliate its citizens could be.

Palabras clave: exclusión social, Modernidad tardía, Derecho penal, política criminal, Estado decente

Keywords:

social exclusion, late Modernity, criminal Law, criminal policy, decent State

\section{CONTEXTUALIZACIÓN. HACIA UNA SOCIEDAD DE LA EXCLUSIÓN}

El propósito de este primer epígrafe es establecer un diagnóstico de la materialidad de la exclusión que caracteriza nuestra Modernidad tardía para poder repensar la legitimidad del Estado de Derecho frente a su ciudadanía.

La tendencia a la exclusión es una deriva que tiene manifestación en múltiples facetas del mundo de la vida. Somos conscientes, como punto de partida, que un Derecho penal eficiente tiene que estar atento a la voz de la ciudadanía; que la política criminal no puede dejarse en manos de expertos. El buen funcionamiento de la justicia penal depende de la implicación y participación de la ciudadanía; su exclusión, tanto a nivel procedimental, como a nivel material -el desamparo y desalojo de los derechos de personas y colectivos- no hace sino ahondar esta problemática. Ahora bien, la justicia penal no es el instrumento adecuado para solventar conflictos y problemáticas que tienen que ver con la justicia social; es necesaria una mirada sistémica en la que se incluya como uno más de sus componentes la justicia penal.

Cierta perspectiva doctrinal considera que un Derecho penal que no respete las instituciones de justicia de la ciudadanía está abocado al fracaso, a la ineficacia ${ }^{1}$. El eje central de este debate es fortalecer el vínculo entre obediencia de las normas y consenso ciudadano; del sólido blindaje de esta bisagra se deriva la legitimidad del Estado para poder castigar ${ }^{2}$. En este sentido, el

1 P. ROBINSON, “The Proper Role of Community in Determining Criminal Liability and Punishment", en RYBERG/ROBERTS (eds.), Popular Punishment. On the Normative Significance of Public Opinion, OUP, Oxford, 2014, pp. 54-75; J. DARLEY, Intuitions of Justice and the Utility of Desert, OUP, Oxford, 2013, pp. 40 y ss.

2 B. FEIJOO SÁNCHEZ, La legitimidad de la pena estatal. Un breve recorrido por las teorías de la pena, Iustel, Madrid, 2014, pp. 50 y ss; A. BOTTOMS, “5 Puzzles in von Hirsch's Theory 
Derecho penal no puede ser sólo materia de sabios y expertos, amparándose para ello en la irracionalidad y falta de conocimiento de la ciudadanía, o en el carácter complejo de la ley ${ }^{3}$; tampoco puede tecnificarse el debate sobre la justicia de las penas amparándose en argumentos como la volatilidad y el carácter etéreo y difuso de la opinión ciudadana, lo que impediría de facto la construcción de foros de ciudadanía deliberativa ${ }^{4}$. Se ha pretendido, también, desacreditar la participación ciudadana al afirmar que su mediación abocaría el Derecho penal a una radical ineficacia ${ }^{5}$, a derivas populistas irracionales, como si participación ciudadana y construcción del Derecho fueran cosas incompatibles, antinomias naturales ${ }^{6}$. La propuesta es que un Derecho penal más participativo y civilizado no produce un Derecho penal menos efectivo ni más punitivo; pero sí más humanitario ${ }^{7}$.

of Punishment", en A. ASHWORTH y M. WASIK (eds.), Fundamentals of Sentencing Theory, Essays in Honour of Andrew von Hirsch, OUP, Oxford, 1998, pp. 53-86.

3 Un sentido crítico con esta perspectiva puede verse J.L. DÍEZ RIPOLLÉS, La racionalidad de las leyes penales, Trotta, Madrid, 2013, pp. 170 y ss.

4 J. RYBERG y J. ROBERTS (eds.), Popular Punishment. On the Normative Significance of Public Opinion, OUP, Oxford, 2014, pp. 106-107. Una perspectiva crítica con el régimen de la democracia deliberativa, por la deriva en la que ésta puede incurrir al convertirse en una mediación para la imposición del punto de vista de una élite concreta, puede verse en $\mathrm{M}$. ROWAN, “Democracy and punishment: A radical view”, Theoretical Criminology, vol. 16 núm. 1,2012 , pp. 43 y ss. No es esta la perspectiva de este escrito.

5 E. ZIMRING, G. HAWKINS, S. KAMIN, Punishment and democracy, OUP, Oxford, 2001.

6 Las criminologías de la vida cotidiana piensan el orden social como un problema de integración sistémica, naturalizando, de esta manera la exclusión como si fuera parte de un proceso lógico y normalizado de los sistemas. Para estas, el orden social es principalmente amoral y tecnológico; el delito, un hecho social al que es necesario acostumbrarse sin excesiva problematización. Cf. D. LOCKWOOD, "Social Integration and System Integration", en Solidarity and Schism, Oxford University Press, Oxford, 1992. Por otro lado, las criminologías del otro peligroso enfocadas hacia una comprensión clásica del delincuente como alguien ominoso y aberrante; el acto delictivo, es, por tanto, una elección perversa no sometida a ningún tipo de condicionamiento, fruto compulsivo de una naturaleza monstruosa. J. BEST, Random Violence: How We Talk About New Crimes and New Victims, University of California, Berkeley, 1999. Ambos enfoques abandonan una comprensión solidaria de los vínculos que construyen ciudadanía, en donde la participación de ésta en la construcción del Derecho resulta fundamental, y por ello, también la recuperación y rehabilitación de la persona delincuente.

7 Autores como S. CÁMARA ARROYO proponen que el principio penal de humanidad de las penas debería ampliarse al concepto de humanitarismo para caracterizar el ordenamiento penal "Justicia Social y Derecho penal: individualización de la sanción penal por circunstancias socioeconómicas del penado (arts. 66.1.6, 20.7 CP y 7.3 LORRPM)", ADPCP, vol. LXVIII, 2015, p. 239. Cf. SANZ DELGADO, El humanitarismo penitenciario español, Edisofer, Madrid, 2003. 
Empezaremos, en este trabajo, haciendo un análisis de las características estructurales que definen la sociedad de la Modernidad tardía, para entender como estos cambios en la configuración social determinan la manera de entender el Derecho penal frente a los procesos de exclusión. Procederemos, por tanto, a realizar una ontología de la exclusión, un análisis de sus condiciones de posibilidad para proyectarlas sobre nuestra propia realidad.

1. La sociedad de la Modernidad tardía que habitamos es una sociedad bulímica donde exclusión e inclusión se producen sincrónicamente; son los rostros de una misma cara que se tensionan y retroalimentan ${ }^{8}$. En nuestras sociedades, inclusión y exclusión son términos constitutivos de una relación binaria, lo que implica que para mantener el orden social es necesario aceptar y negociar sistemáticamente esta relación. Afrontamos, por tanto, el tránsito, en forma de giro epistémico, de una sociedad incluyente a otra excluyente $^{9}$ como consecuencia de la pérdida de legitimidad del Estado social de derecho. Instituciones clásicas como el trabajo, la familia, los vínculos sociales y profesionales, la lucha por la justicia social, o los derechos, ya no proveen una trayectoria sólida y proyectada desde la cuna a la tumba; ya no constituyen un tránsito sin incertidumbres, ni ofertan la seguridad y la solidez de épocas pasadas. Es la exclusión y la pérdida de derechos los vectores definitorios de nuestra estructura social. Pero la díada exclusión-inclusión es acumulativa y se retroalimenta: las personas excluidas utilizan la violencia como respuesta necesaria para vivir en este contexto de exclusión e incertidumbres que las expulsa. Las condiciones de la inclusión de las personas excluidas son la propia violencia de nuestras estructuras sociales. En un contexto así, no existen precondiciones para la implementación real de la responsabilidad.

2. Esta Modernidad tardía es también una sociedad de la externalización, lo que implica deslocalizar exclusión, violencia y pobreza del centro a la periferia de nuestro sistema mundo, a las periferias de nuestros "nortes desarrollados", mediante el sortilegio del gueto y la nueva marginación urbana, siendo víctimas fundamentales de

8 Y. YOUNG, La sociedad excluyente. Exclusión social, delito y diferencia en la Modernidad tardía, Marcial Pons, Madrid, 2003, pp. 23 y ss.

9 Z. BAUMAN, Modernidad y Holocausto, Sequitur, Madrid, 2010; D. HARVEY, La condición de la postmodernidad, Amorrortu, Buenos Aires, 1998, 213 y ss.; G. THERBORN, European Modernity and Beyond, Sage, London, 1995. 
este proceso las personas inmigrantes ${ }^{10}$. Por tanto, producción de riqueza y producción de pobreza/exclusión son rostros desdoblados, pero complementarios del mismo proceso. La desigualdad global es un proceso interactivo y complejo de producción de desigualdades por el que las ventajas de unos son sufridas por los otros; esto es, la sociedad de la externalización permite descargar sobre otros los costos de los estilos de vida propios, a través de asimetrías de poder, mecanismos de explotación pluridimensional y el "habitus de la externalización" ${ }^{11}$; rompiendo, así, con una concepción clásica y dogmática de la desigualdad social explicada sólo a partir de diferencias de ingresos, en el marco del Estado nacional social, sin una comprensión sistémica de los procesos de desigualdad global ${ }^{12}$.

3. La sociedad de la exclusión en la que vivimos se caracteriza también por el pluralismo y la inseguridad ontológica como elementos definidores de su naturaleza. En un contexto de inclusión excluyente, estructurado en torno a formas violentas de existencia y gobernanza, el pluralismo de formas de vida se combina con estructuras que promocionan la inseguridad vital de personas, comunidades y pueblos. Se trata de un pluralismo atenazado por la inseguridad, en el contexto de una cultura del individualismo posesivo, un pluralismo que observa con estupor la pérdida de la cultura de derechos, la disolución de Estados democráticos y constitucionales fuertes como los que nos han precedido, Estados fuertemente intervencionistas, de fiscalidades orientadas al gasto social, que pretendían dar solución a situaciones de exclusión social sin recurrir a la violencia actual ${ }^{13}$. La retórica recuperación económica que caracteriza la post-crisis ha dejado en evidencia que lo que se tambalea son los fundamentos propios de la sociedad democrática. La inseguridad se ha hecho regla de vida por la emergencia de otros factores desestabilizadores como la crisis demográfica, ambiental y política que nos constituye; por la creciente tendencia a la pérdida de vínculos comunitarios -que han funcionado como sostenedores existenciales

10 S. LESSENICH, La sociedad de la externalización, Herder, Barcelona, 2019, p. 51.
11 Ibidem, p. 56; CH. TILLY, La desigualdad persistente, Manantial, Buenos Aires, 2000.
$12 \quad$ S. SASSEN, Expulsiones. Brutalidad y complejidad en la economía global, Katz, Buenos Aires, 2015.

13 T. JUDT, Pensar el siglo XX, Taurus, Madrid, 2012, p. 365. 
de mucha gente-, sustituidos por la conexión digital que no provee seguridad existencial ni vital ${ }^{14}$.

4. Nos encontramos en las antesalas de una paradigma desigualitario $^{15}$ que plantea que un exceso de igualitarismo -de derechos sociales- perjudicaría la economía y el crecimiento de nuestras sociedades e instituciones. En este paradigma, la desigualdad deja de considerarse un defecto que promociona la exclusión de personas y comunidades, para empezar a considerarse como un recurso necesario para el crecimiento. Se produce el reemplazo de los derechos sociales (educación, sanidad, vivienda, formación, pensiones) por el acceso al crédito y el derecho a contraer deudas que implican una promoción y provisión individualizada de derechos mediante seguros individuales, préstamos inmobiliarios, fondos de pensión, en definitiva, una proceso de individualización de las políticas sociales que implican un vaciamiento del Estado social ${ }^{16}$.

5. Todo este contexto desigualitario está implicando cambios en la manera de entender la política criminal como respuesta a los procesos de exclusión social: estamos ante una nueva cultura de control del delito ${ }^{17}$. Podríamos hablar de una suerte de interdependencia y conexión entre las bases materiales de una sociedad; los niveles de delito; los aparatos de control para su disciplina; y la propia doctrina criminológica aplicada. La situación de inseguridad y exclusión que venimos narrando produce efectos inconmensurables en la concepción del castigo penal. Las teorías excluyentes -como la del derecho penal del enemigo- se manufacturan y construyen en tiempos de exclusión social.

6. Esta nueva cultura de control del delito y de la justicia se ha venido construyendo en torno a tres ejes interdependientes: un welfarismo penal ${ }^{18}$ modificado, desnaturalizado; una criminología del

14 FOESSA\&CÁRITAS, VIII Informe sobre exclusión y desarrollo social en España, Fundación Foessa\&Cáritas España, Madrid, 2019.

15 M. REVELLI, La lucha de clases existe... y la han ganado los ricos, Alianza, Madrid, 2014, p. 21.

16 M. LAZZARATO, Gobernar a través de la deuda. Tecnologías del poder del capitalismo neoliberal, Amorrortu, Buenos Aires, 2015, p. 65.

17 D. GARLAND, La cultura del Control. Crimen y orden social en la sociedad contemporánea, Gedisa, Madrid, 2004, pp. 275-313.

18 Por welfarismo hacemos referencia a todo el conjunto de acciones e intervenciones que se producen sobre la cuestión social a partir de las profundas transformaciones que ha 
control; una forma económica de razonamiento y de toma de decisiones. Irrumpen una multitud de indicadores que sedimentan esta cultura del control como: el declive de la idea de rehabilitación ${ }^{19}$; el incremento desmesurado de nuevos tipos penales; cambios importantes en la dinámica emocional de la política criminal ${ }^{20}$; el retorno de la víctima al centro de la escena de la criminalidad, abstrayendo y difuminando las características y motivaciones del delincuente ${ }^{21}$; la politización y nuevo populismo en la manera de entender el delito, los tipos penales y las sanciones ${ }^{22}$; la necesidad de proteger al público, lo público y lo común, por encima de todo, para lo que la cultura del control y la prevención resultan fundamentales; la transformación de las funciones de la policía en una entidad de naturaleza público-privado; la reinvención de la prisión como elemento estrella de la punición; la selectividad en la aplicación de la justicia y en la manera de entender el castigo y la culpabilidad; y un largo etc. Contextos como el descrito constituyen un caldo de cultivo ideal para la consolidación de una criminología administrativa y actuarial más interesada en el control y gestión del delito, que en las causas estructurales que producen y reproducen criminalidad. En una sociedad de la exclusión la práctica criminológica pone su foco de interés en los síntomas, en los elementos accidentales y derivados del delito y de la acción criminal; y no en las causas estructurales y profundas que producen exclusión y propenden a la criminalidad ${ }^{23}$.

sufrido el Estado en los últimos años. También nos referiremos a las estrategias de control del delito que se han desarrollado como consecuencia del ascenso del Estado de Bienestar, como se verá más tarde. Cf. D. GARLAND, Punishment and Welfare: A History of Penal Straegies, Aldershot, Gower, 1985, pp. 15 y ss.

19 La función rehabilitadora de la pena es sustituida por la retribución, la incapacitación o la gestión del riesgo.

20 El enojo, la venganza, la necesaria retribución frente al daño causado; en lugar del afanado compromiso por buscar una solución justa y social a las dinámicas de la criminalidad.

${ }_{21}$ Se produce una reelaboración poderosa del concepto individual y simbólico de víctima, del significado colectivo de víctima en la esfera pública, así como del tratamiento de la misma por parte de las instituciones de justicia penal.

${ }_{22}$ Las tipologías delictivas son hipotecarias, muchas veces, de definiciones y problemáticas socialmente creadas, popularmente alimentadas.

23 Como dice BAUMAN: "El examen de las culpas se disfraza como investigación de las causas". Esta es una sintomatología muy presente en el abordaje de todo proceso de exclusión y victimación; incluso algo que está incrustado en la esencia del discurso de los derechos 
7. En este contexto, la combinación de complejidad (que tiene su expresión en un incremento del delito y el desorden), junto con un aumento de la diversidad, implica cambios profundos en la manera de entender el control y la regulación social. En esta situación, la política criminal tiende paulatinamente a funcionar como un proceso de legitimación de la razón de Estado, de dilución de derechos y de exclusión, a través de procedimientos complejos para la demonización del otro-criminal. Irrumpe una nueva penología del control del riesgo, que se combina sincrónicamente con viejas maneras de entender la punición. Se produce un quiebre en la función monopólica del Estado en el control del delito y un complemento de las funciones del mismo a través de la distribución de responsabilidades entre distintos actores que simultanean funciones de control formal e informal, castigo y prevención ${ }^{24}$.

Varias son las técnicas desplegadas por la política criminal para conseguirlo, abriendo de esta manera un abismo entre el excluido delincuente y el incluido normalizado: a) el distanciamiento, por el cual el delito se explica como una desviación, alejamiento y separación de la persona que delinque respecto a los valores considerados fundamentales en una sociedad; retracción respecto a un corpus compartido de valores, lo que posibilita la generación de un espacio abisal y diferenciado entre nosotros y los otros; b) la esencialización, técnica por la cual proyectamos sobre el otro-delincuente una serie de cualidades que lo hacen esencialmente diferente y desviado respecto a lo que construimos como socialmente bueno y correcto; una maldad -la del otro- socialmente fabricada a partir de una manera esencializante de comprender la desviación y el delito; c) la reafirmación de la normalidad, lo que implica remarcar y fijar bien los límites entre lo nuestro/normal y lo otro/diferente/peligroso/desviado; d) finalmente, la sintetización de todas las fases anteriores en un proceso de demonización que explica la innata maldad del otro a partir de una serie de cualidades socialmente construidas -la del otro/a inmigrante como alguien radicalmente diferente al nosotras/

humanos al intentar abordar una dogmática de la exclusión desde el enfoque de derechos. Modernidad y Holocausto, cit., 2010, p. 16; Cf. Y. YOUNG, La sociedad excluyente, cit., pp. 79-80.

24 D. GARLAND, La cultura del control, cit., pp. 22-23. 
os-, cualidades peligrosas que es necesario modificar a partir de una intensa intervención penal y criminológica ${ }^{25}$.

La estrategia última de estas prácticas y políticas criminales es identificar al otro, esencializarlo y clasificarlo para poder fabricar al monstruo. La esencialización es una técnica que favorece la exclusión social a través de la construcción de estereotipos; la clasificación social de personas y grupos; la normalización a través de la reducción de la diversidad compleja, a la unidad sin rostros ni atributos. Existe, por tanto, una relación interdependiente y trabajada entre esencialismo y exclusión social; la esencialización es una técnica necesaria para paliar la inseguridad ontológica con la que vivimos.

8. Por tanto, en una Modernidad tardía como la descrita se desquebraja el necesario vínculo que tiene que darse entre Estado de Derecho y ciudadanía con derechos, fractura, que en la medida que es coadyuvada por el Estado en la producción de las condiciones materiales de exclusión, pondrían poner en tela de juicio la legitimidad de un Estado para castigar al excluido.

El conflicto en una Modernidad desbocada hacia la exclusión es cuestionarse sobre qué estatuto y legitimidad le queda a la ciudadanía para proceder a la construcción de un Derecho penal humanizado y dialógico. Si no existen resortes para esa posibilidad, para la construcción de una ciudadanía fuerte, la legitimidad de las normas y del Derecho quedan mermadas y la legitimidad para imponer una pena muy cuestionada ${ }^{26}$.

\section{CONDICIONES DE LEGITIMIDAD DE UNA SOCIEDAD DECENTE. UN ANÁLISIS DE ALGUNOS ELEMENTOS DE SU INSTITUCIONALIDAD}

El propósito de este epígrafe es analizar las formas de la institucionalidad democrática necesarias para la construcción y el mantenimiento de una Sociedad Decente. Entendemos por Sociedad Decente aquella que no humilla a sus ciudadanos. Nos interrogamos, por tanto, por las condiciones de

25 Ibidem, pp. 181-188. C. SCHMITT, “Estado, movimiento, pueblo. La triple articulación de la unidad política", Eunomía. Revista en cultura de la legalidad, núm. 12, 2017, pp. 273-309.

26 D. VARONA, "Derecho penal democrático y participación ciudadana", InDret. Revista para el análisis jurídico del Derecho, núm. 2, 2018, pp. 1-47 y J. CIGÜELA SOLA, “El ciudadano y el excluido frente al Derecho penal. Los límites del ciudadano deliberativo de Günther y Kindhäuser y del ciudadano cooperativo de Pawlik", InDret. Revista para el análisis jurídico del Derecho, núm. 2, 2017, pp. 1-35. 
legitimidad que deberían caracterizar el Estado de derecho, y por inferencia, por las condiciones de legitimidad del Estado penal para poder hablar de castigo justo. Para ello haremos un recorrido por algunas dimensiones institucionales de una Sociedad Decente.

Hablar de Sociedad Decente implica enfrentarse a su polaridad: la de una sociedad humillante. Una sociedad humillante es aquella que viola sistemáticamente la autarquía de las personas, siendo la exclusión junto con la falta de participación de la ciudadanía una de las maneras en que se expresa esta violación ${ }^{27}$. Hay que tener en cuenta que el acceso al estatus de la ciudadanía y sus garantías, implica, sincrónicamente, su reverso: la exclusión de los no-ciudadanos de su ámbito de aplicación y disfrute como si de un "bien club" se tratara ${ }^{28}$.

La humillación implica extender la "crueldad del sufrimiento físico al ámbito psicológico" ${ }^{29}$, ese ámbito de la degradación de la persona donde la libertad y la capacidad de auto determinarse desaparece, y las personas y los grupos se hacen dependientes para poder reproducir la existencia. La humillación, en cuanto dependencia, es crueldad mental, puesto que uno se ve y existe sólo a través de los ojos de los otros, condicionado, por sus consideraciones y juicios. El Estado humillante extiende su haz de actuación y dominio a todas aquellas personas que están bajo su jurisdicción. La negación de la ciudadanía, en cuanto negación de derechos -a quien tiene derecho a la ciudadanía pero es negada- es una forma intensa de envilecimiento y humillación ${ }^{30}$. El Estado humillante discrimina en la distribución de bienes y servicios a sus ciudadanos, no atendiendo con la coraza protectora de los derechos el despliegue de la autarquía y la construcción de la independencia personal y grupal.

27 G. JACOBS, "Personalidad y exclusión en derecho penal”, en E. LYNETT (ED.), El funcionalismo en derecho penal, Libro homenaje a Günther Jakobs, Universidad Externado de Colombia, Bogotá, 2003, p. 14.

28 Estamos ante una consideración estrafalaria y perturbadora del Estado-nación como un Club. Los miembros del Club -ciudadanos nacionales- disfrutan determinados bienes, competencias y capacidades, a costa de la exclusión de los no-ciudadanos, para lo que se hace necesario la construcción de toda una arquitectura criminalizante de la "ilegalidad": los que no son miembros del Club, los no ciudadanos, los otros extranjeros, serán expulsados y perseguidos.

29 A. MARGALIT, La Sociedad Decente, Paidós, Barcelona, 2010, pp. 31 y 77.

30 Es más que incongruente sostener que quienes no han podido acceder a la ciudadanía (inmigrantes extranjeros), o quienes la han perdido como consecuencia de sus acciones y nunca la han recuperado (delincuentes), puedan aceptar la autoridad del sistema que los castiga. 
Realizaremos un análisis de las condiciones que dificultan la existencia de una Sociedad Decente -acentuando, con ello, una ontología de la exclusión- teniendo en cuenta algunos parámetros estratégicos, como serían: i) la forma de Estado (de Bienestar) y las consecuencias que una deficiente configuración del mismo ha tenido para la vida de las personas, con una especial referencia a la fragilidad de las relaciones socio-laborales; ii) el tratamiento y gestión de la pobreza; iii) y la consideración del castigo y de la pena.

\subsection{La forma Estado de Bienestar, la flexibilización de las relaciones socio-laborales y su incidencia en la producción de exclusión}

En relación a la forma de Estado es importante matizar que lo que se ha venido llamando eufemísticamente la postcrisis ha implicado la ruptura parcial de grandes pactos sobre los que se arraigaba el Estado de Bienestar. En primer lugar, el pacto fiscal redistributivo. El Estado de Bienestar no se ha planteado, en su radicalidad, cómo afrontar la cuestión distributiva de los recursos entre sus ciudadanos. No ha tenido, entre sus objetivos principales, avanzar hacia la realización de la justicia social ${ }^{31}$. Tampoco ha abordado las causas profundas y estructurales que producen vulnerabilidad y exclusión en nuestros contornos. Su finalidad última era reducir los riesgos; fungir como protector y guardián frente a las fracturas sociales. Su mirada estaba anclada en la necesidad del progreso social como mantra necesario para la reducción de la incertidumbre y la construcción de los derechos. El progreso social estaba concomitantemente asociado a la idea de crecimiento, acumulación y progresión; en la posibilidad de programar y dominar el porvenir, mediante la inscripción de las personas en "colectivos protectores". Lo que contaba eran los derechos adquiridos por el individuo en función del colectivo al que pertenecía y estaba inscrito. Era el estatus -el criterio de pertenencia a un colectivo- lo que otorgaba derechos. Por todo ello, el Estado-nación social ha funcionado como un poderoso factor de individualización, ofertando seguros, protecciones de proximidad; tutelando prestaciones en las que la lógica de los deberes aparecía desconectada de su contracara, los derechos, cuestión fundamental para la construcción de una comprensión sólida de un derecho subjetivo a la existencia ${ }^{32}$.

31 R. CASTEL, La inseguridad social. ¿Qué es estar protegido?, Manantial, Buenos Aires, 2004, p. 47.

32 A. MARTÍNEZ DE BRINGAS, "Los derechos sociales ante la vulnerabilidad: Retos y problemáticas en un marco de flexibilidad y desregulación, Revista Vasca de Administración 
La crisis de este modelo de regulación y protección social, en cuanto paradigma, confluyó con la crisis de los recursos disponibles para seguir alimentando este modelo. Una vez institucionalizada la protección como movimiento unilateral del Estado, la retirada de escena de éste supone un desamparo mayúsculo para una ciudadanía entrenada en recibir, y poco ensayada en la co-responsabilidad. Generar una estructura de dependencia profunda de las personas demandantes de protección, por parte del Estado, para proceder a la deserción estatal en tiempos de múltiples y complejas carencias, implica un serio abandono de una ciudadanía carente y necesitada. Todo ello exige repensar la estructura del Estado en cuanto reductora de riesgos, así como la función que corresponde a los derechos (sociales) para garantizar este objetivo. Un Estado orientado a la protección de viejos riesgos, en tiempos de irrupción de nuevas necesidades y peligros, es un Estado humillante, disfuncional e insostenible ${ }^{33}$.

En este contexto, el precariado laboral se ha convertido en una forma de vida, anudada a un tipo de empleo y a unas determinadas formas contractuales (como la temporalidad y el tiempo parcial), experimentándose síntomas de fuerte pobreza material como consecuencia de los bajos salarios ${ }^{34}$. Unas relaciones socio-laborales como las descritas producen desigualdad múltiple y compleja. En primer lugar, desigualdad de recursos, alimentada fundamentalmente por un mercado de trabajo y unas relaciones socio-laborales como las descritas y que producen fuertes asimetrías en la distribución de la renta de las personas ${ }^{35}$.

De manera interdependiente y sistémica con la anterior, produce desigualdades vitales, lo que se traduce en la conformación de un gran número de problemas sociales y médicos, principalmente en los estratos sociales

Pública, núm. 111 2018, pp. 143-167; “Esbozo de una teoría de los deberes en tiempo de precariedad y exclusión”, Política y Sociedad, núm. 54, vol. 3, 2017, pp. 757-776.

33 E. DEL PINO y M. RUBIO, "El estudio comparado de las transformaciones del Estado de bienestar y las políticas sociales: definiciones, metodología y temas de investigación" en E. DEL PINO y M. RUBIO (eds.), Los Estados de Bienestar en la encrucijada. Políticas sociales en perspectiva comparada, Tectnos, Madrid, 2013, p. 54.

34 De hecho, el nuevo empleo creado es más desigual que el destruido. La población integrada es fundamentalmente aquella que goza de estabilidad en el empleo. Sin embargo, la temporalidad y fragilidad laboral es la condición que permea a las personas en situación de exclusión social severa. Cf. VIII Informe sobre exclusión y desarrollo social en España, cit., p. 40; G. STANDING, El precariado. Una nueva clase social, Pasado y Presente, Madrid, 2013.

35 S. MOYN, Not Enough: Human Rights in an Unequal World, Harvard University Press, Harvard, 2018. 
más excluidos y con menos capacidad de renta. Problemas como: mortalidad prematura, altas tasas de homicidios, fuerte abandono escolar, embarazos prematuros, disminución de la capacidad de movilidad social, emergencia de enfermedades mentales, alto nivel de mortalidad infantil, uso y abuso del alcohol y drogas, etc. Todos estos factores de deterioro de la personalidad coadyuvan de manera determinante en la producción de la criminalidad ${ }^{36}$.

En tercer lugar, desigualdades existenciales, producidas a partir de formas de discriminación racial, sexual, de edad, religión, cultura, etc.

Toda esta comprensión compleja de la desigualdad influye de manera determinante en la toma de decisiones, generando dependencia e impidiendo que personas en riesgo de exclusión social tengan capacidad para prever la urgencia de necesidades sobrevenidas e imprevistas. Incluso en sociedades igualitarias y prósperas la desigualdad rebaja notablemente la calidad de vida de las personas.

Esta sociología de la exclusión no impide que las personas en riesgo de exclusión social tomen decisiones libres que las haga responsables de sus actos; sin embargo, lo hacen en un marco de libertad(es) enormemente condicionado, seriamente recortado y restringido; afectadas seriamente por las circunstancias sociales con y en las que se ha construido y socializado, circunstancias sobre las que no ha habido ninguna libertad de disposición Todas estas cuestiones tienen que tasarse, valorarse y discernirse muy seriamente a la hora de pensar la responsabilidad de un imputado, así como las condiciones generales del delito y de la pena ${ }^{37}$. La persona excluida se

36 R. WILKINSON y K. PICKETT, Desigualdad. Un análisis de la (in)felicidad colectiva, Taurus, Madrid, 2009, J. and P. BLAU, "The cost of inequality The Cost of Inequality: Metropolitan Structure and Violent Crime", American Sociological Revieww, vol 47, núm. 1, 1982, pp. 114-129.

37 Nuestro Código Penal, en el artículo 66.1.6 habla de circunstancias personales del penado como un criterio para la individualización de la pena; como una manera de modificar la responsabilidad criminal. La STS1376/2003 de 24 de octubre considera estas circunstancias personales del delincuente como aquellos rasgos de su personalidad delictiva que configuran esos elementos diferenciales para efectuar la individualización de la pena. Existe además una figura específica que pretende hacerse cargo de las condiciones de precariedad en las que se mueve y vive la persona que delinque, como es el estado de necesidad. Aunque los supuestos para su apreciación son restringidos, ha habido una evolución jurisprudencial favorable en la inexigibilidad de la pena por razón de hurto famélico, aquellas situaciones en las que se produce la sustracción de bienes ajenos para dar salida a necesidades propias que son urgentes y necesarias para la reproducción de la vida. Un análisis de los criterios exigidos por el TS puede verse en: STS de 9 de diciembre de 1985; STS de 21 de enero de 1986; STS de 13 de noviembre de 1989. 
revela, muchas veces, incapaz para discernir y diferenciar moralmente entre el bien y el mal, la legalidad e ilegalidad de determinadas acciones; distancia y confusión respecto a lo que el Derecho determina como justo e injusto. Esta incapacidad pone de manifiesto que el Estado no ha propiciado las medidas y garantías suficientes para que este sector de personas conozca e intervenga en la producción del Derecho, así como para sentirse incluido y socializado por él.

Libertad individual y estructura social actúan de manera interdependiente y trabada, produciendo efectos complejos en ambas direcciones y sentidos. Por ello y en esta tesitura: ¿Debería el Derecho penal explorar las múltiples combinaciones que surgen de esta relación compleja entre libertad individual y estructural social, o debería reducir la complejidad de este maridaje?

Regresando a las condiciones socio-laborales descritas, nos interrogamos: ¿es el trabajo condición de posibilidad para la realización de la dignidad de las personas en una Sociedad Decente?, ¿existen otras pre-condiciones y exigencias de la misma? Una Sociedad Decente: ¿es aquella que garantiza el empleo? o ¿sólo es decente si garantiza la autonomía en y frente al empleo?

De acuerdo con la consideración de Sociedad Decente que venimos manejando, una sociedad sólo será digna si defiende a sus miembros del desempleo masivo y del precariado ${ }^{38}$. Un empleo es algo más que renta y salario. Una sociedad que admite el desempleo involuntario, cercenando la autarquía de las personas, está negando la humanidad del desempleado. Una Sociedad Decente sólo es aquella que garantiza una ocupación con sentido;

La jurisprudencia en España también ha venido considerando otras circunstancias personales del penado para la atenuación y limitación de la pena, como la situación socio-económica y los recursos de los que éste dispone; el estatus social en que se encuentra; la condición existencial que le avala respecto a la comunidad en la que se socializa y respecto a los nexos familiares que mantiene; las condiciones laborales en las que se desempeña; o el riesgo social en el que pueda encontrarse, factores, todos ellos, que han podido ser determinantes para la realización de los hechos delictivos. Cf. STS 256/2008, de 14 de mayo. Se ha considerado, también, que la vida anterior de una persona, la situación actual en la que se encuentra, así como la reacción posterior a los hechos delictivos -desde el anclaje de una interpretación sistémicapueden ser consideradas como circunstancias personales que influyen en la determinación del delito. Cf. STS 470/2011, de 26 de mayo.

38 G. STANDING, El precariado. Una nueva clase social, cit.; La corrupción del capitalismo. Por qué prosperan los rentistas y el trabajo no sale a cuenta, Ed. Pasado y Presente, Barcelona, 2017, pp. 65-180.

DERECHOS Y LIBERTADES

ISSN: 1133-0937

Número 44, Época II, enero 2021, pp. 101-135

DOI: https://doi.org/10.20318/dyl.2021.5851 
no está obligada a dar empleo siempre que oferte otros medios que garanticen la existencia y la vida ${ }^{39}$.

También se produce -en segundo lugar- una fractura del pacto intergeneracional, materializado a través del sistema de pensiones bajo la modalidad del reparto. La fractura del pacto distributivo ha conllevado un descenso alarmante de la natalidad y de la capacidad reproductiva de nuestras sociedades, lo que impide que la solidaridad intergeneracional se pueda seguir manteniendo a partir de un sistema retributivo de pensiones como el hasta ahora sostenido. El estatuto del precariado y la débil estructura de las relaciones laborales que nos habitan producen serias fracturas en la comprensión de los vínculos intergeneracionales y comunitarios que nos han sostenido.

Finalmente, se produce también una fractura del pacto interterritorial, lo que se traduce en un tratamiento asimétrico, diferenciado y desigual de las personas, en función de su lugar de residencia, alejándonos de la ansiada universalidad como criterio catalizador del enfoque de derechos. Una sociedad así, con tal nivel de fractura, está bien lejos de ser una Sociedad Decente y más próxima a la sistemática humillación.

Con todo ello, constatamos el fracaso de la forma Estado de Bienestar para atender y dar salida a la autodeterminación de las personas, a la capacidad de estas para controlar y determinar sus vidas. El Estado de Bienestar humilla cuando nos trata según las normas de la sociedad caritativa ${ }^{40}$. Las relaciones reguladas por lástima -tan propia del bienestariamo que hemos vivido- son asimétricas. La lástima implica una relación de superioridad; despolitiza en la medida que anula y descompone la subjetividad de las personas, su inmarcesible dignidad en cuanto sujeto de derechos. Un Estado humilla en la medida que promociona una institucionalidad que genera dependencia, que produce personas y grupos que carecen de respeto hacia sí mismo $^{41}$.

\subsection{La consideración de la pobreza y la exclusión}

Una expresión sintomática de las dificultades del Estado de Bienestar para producir y reproducir una Sociedad Decente ha sido el tratamiento que se ha venido haciendo de realidades como la pobreza y la exclusión. En la

\footnotetext{
39 A. MARGALIT, La Sociedad Decente, cit., p. 197.

40 Ibidem, p. 188.

41 Ibidem, p. 176.
} 
gestión de estas dos realidades podemos encontramos muchas razones y motivos para sentirse humillado. Someter la pobreza/exclusión a pruebas que acrediten su condición degradada -como ha sido el modus operandi de muchas políticas públicas de derechos- puede resultar humillante. La gestión instrumental de la pobreza/exclusión ha venido, muchas veces, acompañada de un tratamiento estereotipado de estas realidades. La pobreza/exclusión ha sido abordada como una necesidad cognitiva desde patrones que propenden a la clasificación y generalización, simplificando la realidad de la exclusión, sus motivos y causas profundas, reconduciéndola a una esquematización insostenible, y muchas veces humillante. La pobreza/exclusión, en sus múltiples rostros, ha sido abordada poniendo énfasis de manera exclusiva en las dimensiones negativas, transformando rasgos que son productos socio-históricos, culturales y coyunturales, en propiedades innatas e inmutables. Esta gestión de la exclusión es propia de una sociedad que humilla y desprecia. Convertir a las personas que se encuentran en pobreza/exclusión en responsables únicos y libérrimos de su propia situación y condición de vulnerabilidad es un dispositivo discursivo que reproduce prácticas y políticas humillantes. El argumento nuclear desde una perspectiva de derechos, necesario en una Sociedad Decente, no es la eliminación del fenómeno de la pobreza/exclusión -que no es más que una idea transcendental-, sino cuestionarse cómo eliminar la dimensión humillante de la probreza/exclusión.

\subsection{La gestión del delito y de la pena}

Una última dimensión que dificultaría la construcción de una Sociedad Decente sería cómo es abordado y comprendido el régimen de la penalidad y el castigo en una sociedad. Esto es, qué entendemos por un castigo justo y cuando una pena puede resultar humillante por no darse las condiciones de legitimidad necesarias para la imposición de la misma. El reto para la dogmática penal es cómo ser eficiente en la imposición de un castigo/pena sin incurrir en humillación. Cómo compensar el daño que una persona ha hecho a la sociedad a través de la pena, pero sin que ello implique un sufrimiento injustificado y el desprecio más absoluto de su dignidad. Cómo vincular la función de la pena a las condiciones de exclusión en que se produjo el delito, condiciones en cuya reproducción material pueda tener responsabilidad el Estado de Derecho.

Esta hipótesis, que aquí sólo esbozamos, va a ser sostenida como fundamento para cuestionar la legitimidad del Estado en sus formas de punición y 
castigo, en la medida que se pueda demostrar que éste es co-responsable de la producción, reproducción y desarrollo de estructuras sociales que fomentan la desigualdad estructural entre sus ciudadanos. Es paradójico, en este sentido, que la exclusión de derechos venga acompañada de inclusión penal.

\section{EL NUEVO GOBIERNO DE LA PENALIDAD Y SU RELACIÓN CON LOS PROCESOS DE EXCLUSIÓN. UN ANÁLISIS DE SUS CONDICIONES DE POSIBILIDAD}

En este epígrafe abordaremos el vínculo que existe entre la función de la pena y la estructura política del Estado en que cierto derecho penal se inserta, de tal manera que la debilidad democrática de un Estado, la existencia de densas fisuras en su legitimidad, implicaría serias carencias de legitimidad en su capacidad de castigo.

El gobierno de la penalidad en nuestras sociedades contemporáneas está íntimamente relacionado con en el tratamiento de la exclusión social. El maridaje gobierno de la penalidad y exclusión social viene caracterizado, a nivel macro, por:

i) La emergencia de nuevas formas de control social trans-estatal, más descentralizadas y eficaces como consecuencia de la distribución y externalización de la responsabilidad en el control de la seguridad estatal en otros actores. Ello se ha traducido en la conformación de una comunidad de seguridad en el marco de la UE. Esta comunidad de seguridad trans-estatal se caracteriza por el multilateralismo en el tratamiento de preocupaciones comunes: como el control de fronteras y su penalización en el marco de la UE; estrategias para un proyecto militar común; un discurso compartido sobre lo que implica la inseguridad, amenaza y el riesgo; la construcción normativa de un concepto de seguridad cooperativa y colectiva; la coordinación de políticas contra amenazas internas, como el tratamiento del terrorismo; una perspectiva común en la gestión y regulación de los flujos migratorios, etc. ${ }^{42}$ Ello guarda una conexión inextrica-

42 E. ADLER \& M. BARNETT, "A Framework for the Study of Security Communities". E. ADLER \& M. BARNETT (eds.), Security Communities, Cambridge University Press, Cambridge, 1998, pp. 55-57; T. JONES y T. NEWBURN, Private Security and Public Policing, Clarendon Press, Oxford, 1998. 
ble entre penalidad y gestión de la exclusión social en una escala trasnacional.

ii) La sustitución del control disciplinario, tal y como era entendido por Foucault, por un control securitario, más centrado en separar y fragmentar, que en integrar y socializar; en prevenir y anticipar escenarios de control y seguridad, que en castigar ${ }^{43}$. Este nuevo paradigma securitario hace que la vida de las personas y grupos excluidos no sea sometida a un abandono total, al desamparo más impecable; es sometida a un estricto control securitario que controla la exclusión desde la perspectiva criminal y sanitaria, así como desde la planificación y gestión de espacios urbanísticos que distribuyen y re-asientan la exclusión (la biopolítica de Foucault). De esta manera, los espacios públicos urbanos se transforman en función de los excluidos. Se estereotipa su peligrosidad hasta el punto de generar espacios concentracionarios urbanos que implican el cercamiento del espacio público por la peligrosidad innata que ciertos grupos y sectores representan para lo común ${ }^{44}$.

iii) La irrupción de tecnologías digitales que constituyen una sustitución del panoptismo hasta ahora desarrollado. Por todo ello, el excluido está mucho más determinado a ser calificado como un sujeto que produce riesgo social ${ }^{45}$.

43 Garland, por ejemplo, advierte de un cambio en las estrategias de prevención del crimen, donde la exclusión y la vigilancia estarían tomando el lugar que las políticas sociales y criminológicas fungían en el marco del Estado de Bienestar social. La prisión se presenta como un mecanismo de exclusión y control, más que de rehabilitación e inserción, dirigido fundamentalmente a personas que engrosan la categoría de excluidos sociales. Cf. D. GARLAND, La cultura del control. Crimen y orden social en la sociedad contemporánea, cit., p. 291.

44 L. WACQUANT, Parias Urbanos. Marginalidad en la ciudad a comienzos del milenio, Manantial, Buenos Aires, 2003, pp. 165-187. Cf. J.L. DÍEZ RIPOLLÉS, “El control de espacios públicos como técnica de exclusión social". Revista Española de Investigación Criminológica, vol. 4, núm. 12, 2014, pp. 1-28. WACQUANT escribió una trilogía sobre las relaciones imbricadas e interdependientes que existen entre la pobreza/exclusión/etnicidad, Estado social y Estado penal, donde formula la emergencia de un nuevo régimen de pobreza urbana que llama "marginalidad avanzada", en cuanto categoría que suplanta el gueto urbano americano y el territorio obrero tradicional europeo, siendo todo ello producto de la fragmentación del precariado, de la estigmatización del territorio, de la intensa urbanización de finales del siglo XX, así como de la retracción y recorte de las protecciones que ofertaba el Estado social.

45 J. CIGÜELA SOLA, Crimen y castigo del excluido social. Sobre la ilegitimidad política de la pena, Tirant lo Blanch, Valencia, 2019, pp. 132 y ss. 
Procederemos estableciendo las condiciones generales, en forma de tesis, con las que se expresa la función penal del Estado -la gubernamentalidad de la pena-, llamando la atención sobre la relación interdependiente que se produce entre ésta y los procesos de exclusión social. Esto es, cómo el disciplinamiento y castigo del excluido dan sentido y contenido a la dimensión penal del Estado; y cómo se ha venido penalizando el tratamiento de la pobreza/exclusión ${ }^{46}$.

1. Existe un vínculo interdependiente entre las causas sociales de la exclusión y la criminalización; entre política social y política penal; entre Estado social y Estado penal. Evidenciamos, por tanto, la existencia de una continuidad y retroalimentación entre exclusión y criminalización. Dicho vínculo se expresa a partir de una explicación del delito como exclusiva responsabilidad individual del delincuente, complementado con una configuración distorsionada del concepto de inseguridad pública ${ }^{47}$. Desde ahí, se produce una suerte de fractura en la continuidad que existía hasta ahora en el binomio crimen-castigo. A partir de ahora, el Estado penal se justifica por la entrada en escena de múltiples factores, entre ellos un régimen de inseguridad social construido para explicar la peligrosidad que dimana de los estratos sociales más bajos y excluidos ${ }^{48}:$ "(...) la penalización de la pobreza ha resultado ser un vector prolífico para la construcción de la realidad social y para la reorganización del Estado, ahora inclinado hacia la imposición de la inseguridad social en la era del capitalismo desregulado" ${ }^{49}$. A ello hay que añadir otro

46 Seguiremos de cerca trabajos basales para esta contextualización como son las obras de L. WACQUANT, Castigar a los pobres. El gobierno neoliberal de la inseguridad social, Gedisa, Barcelona, 2012; Las cárceles de la miseria, Manantial, Buenos Aires, 2000.; D. GARLAND, La cultura del control, cit.

47 La invención de la inseguridad y su imaginario se corresponde con todo un mercado de seguridad privada-pública; de la distribución de responsabilidades en la función del control social a múltiples actores, agencias e instituciones. Cf. Las Cárceles de la miseria, cit., pp. 97 y ss.

48 L. WACQUANT, Castigar a los pobres, cit., p. 407.

49 Ibídem, p. 417; Cf. También "El cuerpo, el gueto y el Estado penal" en Apuntes de Investigación/Oficios y Prácticas, 2007, pp. 123 y ss.; "The penalisation of poverty and the rise on neoliberalism", European Journal on Criminal Policy and Research, núm. 9 vol. 4, 2001, pp. 401-412; "Poner orden a la inseguridad. Polarización social y recrudecimiento punitivo" en Revista Catalana de Seguretat Pública, mayo 2011, pp. 141-155. Quienes más sufren, por tanto, el peso de la ley penal son las personas excluidas; históricamente han sido mejor tratados por la justica quienes se encuentran socialmente más favorecidos, fuera de los patios de la exclusión. 
factor explicativo de la inseguridad social que tiene incidencia en la praxis criminal, como es el proceso de flexibilización y precarización del empleo, lo que proyecta un cúmulo de inseguridad existencial sobre el todo social, sin que se analicen las causas estructurales que han llevado a este proceso de desmontaje de las regulaciones socio laborales $^{50}$. La inseguridad social que sufre el precariado se proyecta como desesperación en sus acciones y ello modula la política criminal del Estado en el tratamiento de estas formas de exclusión. Sin embargo, esta atención obsesiva por el delito distrae la atención sobre lo que serían las causas estructurales y profundas de la pobreza/exclusión en nuestras sociedades.

2. El desmoronamiento del Estado social, con el incremento del Estado económico neoliberal, lleva también consigo la expansión del Estado penal, dando lugar a un tratamiento penal de la exclusión. El Estado social, en los últimos años, ha estado condicionado por la cualidad moral de sus beneficiarios. Ahí residen algunas de las razones que explican su fracaso. Los requisitos de reinserción para las personas excluidas se han hecho enormemente gravosos, condicionados por la cualidad de su exclusión (nacional o extranjero; hombre o mujer, etc.); por la idoneidad de sus comportamientos y actitudes ante la inserción; por la adaptación mansa y flexible hacia lo que hemos llamado el paradigma de ciudadano-trabajador como engranaje fundamental de comprensión y acceso a los derechos. A ello habría que sumar los trámites de una administración burocrática que retrasaba hasta la extenuación las exigencias de un colectivo (excluido) que no pueden permitirse retrasos en la percepción de las ayudas ni en la gestión de su condición vulnerable ${ }^{51}$.

3. El consiguiente descompromiso y desvinculación del Estado post-social respecto a sus ciudadanos. Las políticas sociales, orientadas sobre todo a los sectores más excluidos, se caracterizan por el laissez-fair y el

Cf. Ma I. SERRANO MAÍLLO, “Delincuencia y pobreza. La economía de los presos”, Boletín de la Facultad de Derecho, UNED, núms. 8-9, 1995, 435-444.

50 V. DE GAGULEJAC, Las fuentes de la vergüenza, Sapere Aude, Asturias, 2015. Este desarrolla una suerte de economía política de la vergüenza y sus efectos sobre las relaciones laborales. Analiza el efecto que la vergüenza produce sobre aquellos que padecen una situación laboral precaria y excluyente.

51 S. MESA, Silencio Administrativo. La pobreza en el laberinto burocrático, Anagrama, Barcelona, 2019. 
laissez-passer, lo que se traduce en una indiferencia del Estado respecto a las personas y grupos excluidos; un llamado a la no intervención y a la desvinculación Estado-comunidad como estrategia para afrontar la exclusión. Esta desvinculación y descompromiso del Estado es falsa y retórica, puesto que, en paralelo, hay un proceso de intensa y meditada intervención para facilitar control social -a través de múltiples actores y agencias-, lo que implica una densa disposición a la regulación de la exclusión mediante el despliegue de todo un aparato securitario que limita derechos. La política criminal combina de manera simultánea máxima e intensa responsabilidad penal del excluido; junto con una gran benevolencia y permisibilidad hacia prácticas de impunidad y corrupción producidas por sectores sociales con poder e influencia social ${ }^{52}$. Ello remarca la importancia del vínculo existente entre función de la pena y estructura política concreta del Estado en que se inserta el Derecho penal ${ }^{53}$, como condiciones de posibilidad para valorar la legitimidad de un castigo justo.

Este maniqueísmo social implica la calificación de las personas criminales/excluidas como seres invisibles portadores de un estigma que los con-

52 Durante la tramitación parlamentaria del Código penal español, operada por la Ley Orgánica 1/2015, de 30 de marzo, por la que se modifica la Ley Orgánica 10/1995, de 23 de noviembre, se aludía, entre otras críticas, al "excesivo garantismo para algunos delitos económicos relacionados con la corrupción urbanística y el blanqueo de capitales" (Diario de Sesiones del Congreso de los Diputados. Pleno y Diputación Permanente, de 12 de diciembre de 2013, p. 27). De la Rocha Rubi, indicaba que "El Código Penal del Partido Popular era, una vez más, duro frente al débil -elevaba exponencialmente penas en delitos ordinarios- y débil frente al fuerte, débil frente al corrupto" (Diario de Sesiones del Congreso de los Diputados Comisiones, de 16 de enero de 2015, p. 14); "instamos una vez más la derogación paralela del artículo 307 ter, el famoso delito de obtención de prestaciones indebidas a la Seguridad Social por parte de los trabajadores, tanto más grave por la desigualdad tan radical que significa entre los defraudadores tributarios, los socialmente considerados corruptos, y los trabajadores que defraudan a la Seguridad Social. Sabemos que los primeros, los ricos y muy ricos, para cometer delito fiscal hoy tienen que defraudar al menos 120.000 euros al año, mientras que el pobre, el parado, el trabajador que compatibiliza el trabajo con un día o una semana de prestaciones de desempleo u otras ayudas públicas comete delito desde el primer euro. Como hemos dicho muchas veces es una nueva y dramática manifestación de un derecho penal de clase que habría que superar, señorías, y que este Código Penal mantiene" (Ibídem, p. 15). De manera más enconada, Baldoví Roda, quien llega a asegurar que en la reforma "el sistema judicial penal es un mecanismo de represión de la disidencia y de la pobreza y no de cohesión social y convivencia" (Diario de Sesiones del Congreso de los Diputados. Pleno y Diputación permanente, de 21 de enero de 2015, p. 27).

53 D. VARONA, "Derecho penal democrático y participación ciudadana", InDret, 2, 2018, pp. 1-47.

ISSN: 1133-0937

DERECHOS Y LIBERTADES

DOI: https://doi.org/10.20318/dyl.2021.5851

Número 44, Época II, enero 2021, pp. 101-135 
vierte en desviados sociales; entes con una identidad deteriorada. Es, precisamente, esta mirada la que hace de la desigualdad y de los procesos de exclusión un factor muy poderoso para la producción de criminalidad.

\section{RESPONSABILIDAD DEL ESTADO E (IN)JUSTICIA SOCIAL. CRÍTICA DE LA LEGITIMIDAD DEL CASTIGO EN MARCO DE UNA SOCIEDAD EXCLUYENTE}

Este epígrafe realizará un pequeño recorrido por algunas doctrinas y teorías penales para poder entender cómo es valorada la espinosa cuestión de la responsabilidad de un Estado que ha participado en la exclusión de una parte de su ciudadanía desamparándola, para discernir la legitimidad moral del Estado en la imposición de castigos a personas que hayan delinquido, conscientes que la situación de exclusión en las que se encontraban ha influido notablemente en la producción del acto delictivo.

Para ellos nos apoyaremos en dos tipos de razonamiento: i) aquel que tiene que ver con razones internas del sujeto y que tendría conexión con motivaciones de psicología social: esto es, cuáles son las razones profundas e íntimas que fundamentaron la incapacidad de una persona para guiarse internamente y reconocer la obligatoriedad de una norma. Interrogarse sobre dónde se produjo la fractura -cuáles fueron los condicionamientos últimos e inmediatos- para que una persona en riesgo de exclusión no reconozca una norma como obligatoria; o, en qué medida la falta de socialización y de participación de la ciudadanía en la construcción del Derecho ha implicado desafección ciudadana y ha influido en la realización de la acción criminal del sujeto; ii) aquel que tiene que ver con razones estructurales, esto es, cuál es la legitimidad del Estado para imponer un castigo, cuando él mismo ha sido co-responsable del desamparo estructural de personas y grupos ${ }^{54}$. Vamos a proceder sistematizando algunas propuestas doctrinales, desde el enfoque metodológico que nos interesa: los presupuestos que caracterizan una Sociedad decente.

1. La tesis de la incapacidad se enuncia desde una pregunta fundamental: ¿por qué la mayor o menor injusticia social de nuestras sociedades podría incidir en la ilegitimidad del castigo de personas que son culpables de cometer delitos? La tesis de la incapacidad ubica como fundamento de su argumen-

54 A. DUFF, Sobre el castigo. Por una justicia penal que hable el lenguaje de la comunidad, Siglo XXI, Buenos Aires, 2015, pp. 136 y ss.

DERECHOS Y LIBERTADES

ISSN: 1133-0937

Número 44, Época II, enero 2021, pp. 101-135

DOI: https://doi.org/10.20318/dyl.2021.5851 
tación la conexión inextricable que existe entre injusticia social e incapacidad moral para castigar. Esta tesis parte del supuesto de que la exclusión social es el resultado de un proceso de injusticia estructural, siendo las víctimas más sensibles y afectadas por esta situación las personas en riesgo de exclusión ${ }^{55}$. Lo importante para esta tesis es remarcar cómo la condición social de exclusión propende a la producción de ilícitos penales, en el marco de una contexto estructural de injusticia y vulnerabilidad ${ }^{56}$. El problema reside en la legitimación que un Estado excluyente presenta para imputar como responsables últimos a los excluidos-víctimas, por hechos penalmente antijurídicos ${ }^{57}$.

De manera sintética la tesis se podría exponer como sigue: el castigo penal es moralmente ilegítimo si se aplica: i) a los excluidos sociales y ii) los delitos por los que se aplica tienen una conexión relevante con la exclusión que sufren. Hay, por tanto, una relación de causa-efecto en todo el proceso. Todo ello sin que la persona excluida resulte exonerada de responsabilidad por el delito cometido.

La tesis de la incapacidad puede apreciarse también en aquellas perspectivas doctrinales que consideran el castigo penal como un reproche moral. El castigo es, en definitiva, una manera de reprochar por el acto cometido (ilícito). Puede darse una pérdida de la legitimidad moral para reprochar en varios supuestos: i) cuando el que reprocha puede ser criticado como responsable por la realización de una conducta similar a la que critica; ii) cuando el reprochante (Estado) es co-responsable y co-productor de lo que critica; iii) cuando el que reprocha ha incumplido deberes básicos hacia la ciudadanía que puedan motivar la realización de esos ilícitos ${ }^{58}$.

55 Esta tesis se refiere sólo a ciertas personas con una historia vital trufada de carencias existenciales, lo que implica una deficiente socialización y una precarización vital tal que impide discernir cualquier referencia moral sobre lo bueno o lo malo; o los fundamentos que sustentan ciertas obligaciones jurídicas y comunitarias. Personas maltratadas sistemáticamente por el sistema penal de un Estado; personas que carecen de las capacidades necesarias para poder entender su propia condición de acusado o el carácter delictivo de la conducta que se le imputa, etc.

56 R. DELGADO, "Rotten Social Background: Should The Criminal Law Recognize a Defense of Severe Environmental Deprivation", Law and Inequality, núm. 3, 1985, pp. 9-90; A. DUFF, "I Might Be Guilty, but You Can't Try Me: Estoppel and other Bars to Trial”, Ohio State Journal Of Criminology and Law, núm. 1, 2004, pp. 245-259.

57 J.M. SILVA SÁNCHEZ, "Presupuestos socio-políticos de la atribución de responsabilidad penal", en Fernández Teruelo (ed.), Estudios penales en homenaje al profesor Rodrigo Fabio Suárez Montes, Constitutio Criminalis Carolina, Oviedo, 2013, p. 732.

58 E. RIVERA LÓPEZ, "Castigo penal, injusticia social y autoridad moral", Análisis Filosófico XXXV, núm. 2, 2015, pp. 174 y s.

ISSN: 1133-0937

DOI: https://doi.org/10.20318/dyl.2021.5851
DERECHOS Y LIBERTADES

Número 44, Época II, enero 2021, pp. 101-135 
Tadros es muy contundente al respecto cuando afirma que si el Estado ha causado o participado de manera relevante en la producción del contexto de exclusión social, el Estado es co-responsable, en última instancia, de esa situación, así como de los daños que se puedan derivar de la misma ${ }^{59}$. Por tanto, el Estado no puede castigar a las personas excluidas si se ha portado mal con ellas, si las ha tratado de manera humillante. Ahora bien, si el delito es desproporcionadamente más grave que el maltrato o desamparo recibido, ese maltrato no anula la legitimidad del Estado para castigar. Esta necesaria ponderación alude, indefectiblemente, al tipo de bienes jurídicos dañados por las personas excluidas, estando la imposición de la pena fundamentada cuando la acción criminal afecte a bienes tan importantes como la vida, o la integridad física y psíquica de otras personas. Ahora bien, si se tratará de afectación a bienes jurídicos de menor cualidad e importancia que los referidos, la tesis de la incapacidad podría resultar más plausible de aplicar por ponderación de bienes jurídicos en conflicto. No deja de ser importante - para esta tesis- el cuestionamiento de la autoridad moral del Estado para castigar cuando se dan ciertas condiciones que hagan al Estado corresponsable del daño causado. Ello es así por la dimensión relacional existente entre el delito y la violación de derechos que también ha sufrido el delincuente ${ }^{60}$.

2. La tesis retribucionista sostiene que la imposición de un castigo no implica necesariamente una condena moral; sólo la asignación de aquello que el delincuente merece. Existen varias versiones de esta teoría ${ }^{61}$, sin embargo, es la postura de Murphy la que está más próxima a nuestros argumentos. Murphy propone que el castigo es el pago que el delincuente realiza para reestablecer la relación de equidad con la sociedad. Ahora bien, para nuestro autor, si la sociedad es injusta, si estamos en las antesalas de un Estado humillante, éste no puede exigir el cumplimiento del castigo de aquellos que sufren o están en

59 V. TADROS, "Poverty and Criminal Responsabilty", Journal of Value INquiry, núm. 43, pp. 404-409.

60 La argumentación podría gozar de más claridad en el supuesto de los desahucios. Una persona desahuciada en un contexto de injusticia estructural -donde el derecho habitacional de las personas decae frente a otros intereses o bienes jurídicos, como los del mercado o la banca- estaría legitimada para la ocupación de un espacio que la permita vivir y reproducir su vida, quedando, bajo nuestra perspectiva, desautorizado y deslegitimado el Estado para interponer un castigo si no ha ofrecido alternativas habitacionales. 117-205.

61 J. P. MAÑALICH, “La pena como retribución”, Estudios Públicos, núm. 108 2007, pp. 
una situación de exclusión social que ha sido producido en alguna medida por el Estado. En estas condiciones el castigo no retribuiría nada, no establecería ningún equilibrio en la falla producida entre el ciudadano que delinque y el Estado. En este supuesto el castigo no haría más que institucionalizar y perpetuar la situación de injusticia estructural establecida. Quien no ha obtenido bienes de cooperación, ni ha sido beneficiario de una justa política distributiva -siendo, por tanto, una víctima del sistema-, no se le puede imputar que retribuya a la sociedad por los daños causados ${ }^{62}$. Esta propuesta es más ambiciosa que la tesis de la incapacidad y va más lejos que ella al establecer que el Estado (humillante) no sólo carece de legitimidad y autoridad moral para castigar, sino que los delincuentes que son objeto de exclusión social en situaciones extremas no merecen ser castigados por no haber recibido los beneficios de inserción -en forma de derechos- que como ciudadanos les corresponden.

Difícilmente podemos afirmar que las personas excluidas hayan participado en la construcción, o prestado su asentimiento para el desarrollo de las normas que las obligan. Podemos constatar una fractura del vínculo de pertenencia como ciudadanía de todas estas personas que son víctimas de una deficiente socialización y protección por parte del Estado. Se podría decir que no hay culpabilidad, en sentido estricto, allí donde no ha habido posibilidad de acceso al proceso productivo de las normas; allí donde la comunidad ha sido desplazada y excluida de la producción del bien común a través del Derecho. Nos referimos a la dimensión necesariamente participativa que debe producirse en el pacto ciudadanía-Estado, tanto en la dimensión horizontal, como vertical del proceso democrático y de su concomitante producción legislativa. Sólo puede haber retribución comunicativa si hay condiciones de justicia distributiva en un Estado ${ }^{63}$.

Se podría cuestionar, como hace Seelmann, que un Estado “defectuosamente organizado que genere embrutecimiento tenga todavía un derecho moral a la imputación jurídica penal de delitos que están condicionados por su comportamiento incorrecto" ${ }^{\prime 64}$.

62 J. MURPHY, “Marxism and Retribution”, Philosophy E Public Affairs, vol. 2, pp. 217-243.

63 J.P. MAÑALICH, "Justicia, propiedad prevención" en La ciencia penal en la Universidad de Chile: libro homenaje a los profesores del Departamento de Ciencias Penales de la Facultad de Derecho de la Universidad de Chile, J. P. MAÑALICH (coord.), Universidad de Chile, Santiago de Chile, pp. 167-187.

64 SEELMANN, "La dispersión de la responsabilidad como límite de la pena", en R. ROBLES PLANAS (ed.), Limites al derecho penal. Principios operativos en la fundamentación del castigo, 2012, p. 220. 
3. La propuesta de Duff -desde una perspectiva comunicativa del castigo, un proceso que fluye de manera bidireccional entre la comunidad política y el delincuente- también posee gran interés para nuestras pretensiones cuando propone que la responsabilidad penal en sí misma es un proceso, no un simple hecho fáctico y jurídico. El autor se interroga con proyección ¿quién puede hacer penalmente responsable a alguien de algo? Habíamos partido en la primera parte de este trabajo del hecho de que la legitimidad viene dada por la necesidad de tratar a alguien como ciudadano; esto es, moverse en las premisas del Estado decente que proponíamos. De no ser así, la comunidad no está en condiciones de reprochar nada a nadie ${ }^{65}$. Duff propone incorporar la dimensión de la justicia restaurativa como medio fundamental para reparar la situación dañada por un delito. El derecho penal debe insertarse, por tanto, en el diseño de procedimientos de justicia flexibles, que permitan equilibrar y recoger de manera más simétrica la responsabilidad de las partes confrontadas, a partir de un principio comunicacional entre personas, comunidad y el Estado. Duff habla de "las precondiciones necesarias para la justificación de la justicia penal" ${ }^{66}$, lo que significaría evidenciar una grave falta de reciprocidad en la prestación de determinados servicios estatales, con determinados sectores sociales. A ello habría que adicionar una posible contexto de injusticia social estructural promovida y coadyuvada por el propio Estado ${ }^{67}$.

Prolongando la idea anterior, Duff propone una concepto relacional de responsabilidad ${ }^{68}$. Dicha dimensión relacional implica una conexión estructural entre responsabilidad y razones para hacer o no hacer. Somos respon-

65 A. DUFF, Punishment, Communication, and Community, Oxford University Press, Oxford, 2001, pp. 195-196; Sobre el castigo. Por una justicia penal que hable el lenguaje de la comunidad, Siglo XXI, Buenos Aires, 2015, p. 144.

${ }_{66}$ Habla de cuatro tipos de impedimentos que abortarían gravemente esas precondiciones, como son: la capacidad del acusado para conocer y responder a la imputación; la conducta típica que se le imputa; la pertinencia de las pruebas que se le imputan; la legitimad de la autoridad que la obliga a responder por el delito cometido. A. DUFF, Sobre el castigo. Por una justicia penal que hable el lenguaje de la comunidad, Siglo XXI, Buenos Aires, 2015, p. 76.

67 "Cualquier teoría que haga de la justicia del castigo aplicado a un delincuente un factor crucial de su justificación debe enfrentar el siguiente problema: ¿es posible castigar justamente a delincuentes cuyos delitos guardan íntima relación con las graves injusticias sociales que han sufrido?". Una manera de responder sería que el Derecho debería reconocer como defensa especial la alegación de una marcada desventaja social del imputado. Sobre el castigo, cit., p. 144.

68 Ibidem, pp. 97-115.

DERECHOS Y LIBERTADES

ISSN: 1133-0937

Número 44, Época II, enero 2021, pp. 101-135

DOI: https://doi.org/10.20318/dyl.2021.5851 
sables de lo que tenemos razones para hacer. El sujeto penalmente responsable es aquel que se puede comprometer con los tipos de razones para la acción que proporciona un Estado a través del Derecho penal ${ }^{69}$. Un Estado humillante que desampara a las personas excluidas no proporciona este tipo de responsabilidad al no generar motivos para la acción y el compromiso por parte de la persona excluida. En este sentido, sólo somos responsables por lo que está dentro de nuestro control; la responsabilidad se desvanece si el Estado no nos otorga capacidades para ejercitar y conformar ese control responsable. Por tanto, lo que podríamos pedir a la justicia penal es que facilite y promocione el regreso a la "ciudadanía" plena a quienes han cometido delitos; o a quienes se les ha negado y desde esa carencia los cometen. Un proceso que permita la restauración de la dignidad desde los derechos, evitando, por el contrario, tratar como ciudadanos a aquellos que, por sus delitos, han negado los lazos de ciudadanía ${ }^{70}$.

4. Desde la perspectiva de América Latina, resulta relevante la aportación de Gargarella. En relación a la legitimidad del castigo del excluido social por parte del Estado considera como eje central de su hipótesis la necesidad de establecer "deberes morales de reciprocidad". Nuestro autor considera que en situaciones de "alienación legal", esto es, situaciones de sistemática violación de derechos que inevitablemente comprometen el sistema legal ${ }^{71}$, el Estado pierde autoridad para seguir ejerciendo su poder coercitivo en materia penal; ello nos obliga a cuestionar la validez misma de las normas vigentes que se nos presentan como legítimas ${ }^{72}$. Exige examinar

69 Pillsbury llega afirmar que la responsabilidad moral de una persona depende de la participación en la discusión continua sobre el significado de la vida humana, nicho y contexto de discusión de la que queda arrancado sin miramientos el sector de las personas en riesgo de exclusión. S. PILLSBURY, Judging Evil: Rethinking the Law of Murder and Manslaughter, New York University Press, New York, p. 120; D. HOUSAK, "Does Criminal liability require and act?, en A. DUFF (comp.), Philosophy and the Criminal Law: Principle and Critique, Cambridge University Press, Cambridge, 1998, pp. 60-100.

70 DUFF, Sobre el castigo, cit., p. 46.

71 R. GARGARELLA, "El derecho y el castigo. De la injusticia penal a la justicia social", Derechos y Libertades, núm. 25, 2011, p. 42; "Penal Coercion in Contexts of Social Injustice" en Criminal Law and Philos, 2011, 5, pp. 21-38; R. GARGARELLA (coord.), El castigo penal en sociedades desiguales, Miño y Dávila, Buenos Aires, 2012; De la injusticia penal a la justicia social, Siglo del Hombre/Universidad de los Andes, Bogotá, 2012.

72 Cf. En este sentido el magnífico artículo de M. BERMAN, "Punishment and Justification", Ethics, vol. 118, núm. 2, 2008, pp. 258-290. 
y valorar constantemente el poder coercitivo del Estado, siempre con una presunción negativa respecto a la validez del uso de la fuerza penal, en trabada interdependencia con la prolongación en el tiempo de situaciones de injusticia estructural promocionadas por el Estado ${ }^{73}$. En estas condiciones, el Estado puede castigar al excluido siempre que pueda revertir y dar salida a las situaciones endémicas de injusticia social en que se encuentra el excluido social, esto es, permitir una integración de la situación de exclusión por medio de derechos. Gargarella se muestra crítico, necesariamente, con los injustificados modos en que se ejerce la violencia estatal en América Latina, proponiendo, sin embargo, búsquedas alternativas a la resolución de conflictos penales, asumiendo como límite a la racionalidad penal del Estado, los derechos de las personas excluidas y más golpeadas por el sistema penal.

5. Es necesario hacer referencia a los autores que ubican la ciudadanía deliberativa como el centro desde el que fundamentar jurídica y políticamente la pena, como Klaus Günther y Mañalich, entre otros. Günther hace una trasposición al Derecho penal de la teoría discursiva de Habermas ${ }^{74}$. Serían válidas aquellas normas en la que todas las personas afectadas pudiesen participar en su construcción y desarrollo a partir de discursos racionales. Es la participación ciudadana, a partir del discurso, la que construye la norma; el discurso permite que la ciudadanía se dé a sí misma una normativa y queden vinculados y obligados por ella. Por tanto, podemos hablar de castigo legítimo en la medida que se aplique a ciudadanía deliberativa. De ahí se infiere que si no es posible deliberación ni participación en la construcción de las normas estas no serán legítimas. Se hace depender la obediencia ciudadana a la norma y, desde ahí, la legitimidad del castigo, de la existencia de un régimen y unas condiciones democráticas en el Estado. Sólo un Estado democrático, que permita la participación discursiva de sus ciudadanos, que los

73 "En lugar de presumir, como hacemos hoy, que el ejercicio del poder punitivo se justifica en todos los casos, tenemos que cambiar la presunción y obligar al Estado a que nos justifique por qué quiere hacer lo que viene haciendo, dado el contexto social que existe, y del que es directo responsable. (...) la presunción debe invertirse hasta tanto el Estado no demuestre que está haciendo esfuerzos genuinos y visibles para cambiar la situación que hasta hoy mantiene y que comporta masivas y graves violaciones de derechos", R. GARGARELLA, "Injusticia penal y justicia social" en El castigo penal en sociedades desiguales, Miño y Dávila, Argentina, 2012, p. 128.

K. GÜNTHER, “Un concepto normativo de coherencia para una teoría de la argumentación jurídica”, DOXA, núm. 14-15, 1995, pp. 274-302. 
capacita y promociona para la participación en la construcción del Derecho y el Estado, puede imponer legítimamente penas a su ciudadanía ${ }^{75}$, con independencia de que luego esos ciudadanos decidan o no participar.

La contracara crítica a las teorías de la ciudadanía deliberativa sería constatar si la persona excluida forma parte de la ciudadanía deliberativa; o la exclusión es ya una manera de apartamiento de las capacidades y posibilidades que corresponden a este modo de ciudadanía. ¿No es la exclusión la que inhabilita potencialmente para deliberar a estas personas? ¿No son, precisamente, las personas excluidas, las que también han quedado fuera de cualquier mesa de diálogo ciudadano?; ¿para quienes la deliberación cívica es un recurso inalcanzable?

Más sutil resulta la concepción de ciudadanía cooperativa de Pawlik. El ciudadano cooperativo es aquel que tiene la responsabilidad de cooperar para poder mantener el estatus de libertad ${ }^{76}$. El ciudadano coopearativo se mueve desde las posibilidades que oferta la conjunción de derechosdeberes. La cooperación es una responsabilidad para garantizar la libertad, la paz social en el marco del Estado; la contraprestación de esa ciudadanía activa y cooperativa es el cincho de seguridad y protección que por medio de derechos el Estado oferta. El ciudadano cooperativo influye y confluye en los procesos democráticos a partir de la lógica de derechos-deberes. El Estado sólo considerara ciudadanos responsables a aquellos que son objeto de protección y, que, como consecuencia de este blindaje del pacto social, se comprometen a cooperar. Por tanto, sin protección no hay cooperación. Ello afecta de manera directa a la médula de nuestra propuesta: ¿qué pasa con la persona excluida, abandonada y desamparada por el Estado, que no ha sido objeto de protección, ni de cuidado por parte de éste? ¿Cuál es la responsabilidad de este tipo de persona respecto al Estado, si sólo le corresponden deberes de cooperación, pero no derechos? ¿Le vinculan las normas de igual manera que a otros ciudadanos cooperativos? ¿qué legitimidad tiene el Estado para imponer una pena a un ciudadano al que no ha protegido con la seguridad de los derechos y el amparo del Estado? ${ }^{77}$ Para Pawlik está claro

75 P. MAÑALICH, "Pena y ciudadanía”, en U. KINDHÄUSER y P. MAÑALICH, Pena y culpabilidad en el Estado democrático de Derecho, BdF, Buenos Aires, 2011, p. 227.

76 M. PAWLIK, Ciudadanía y Derecho penal, Atelier, Barcelona, 2016, p. 125.

77 En su reciente visita a España (febrero de 2020), el Relator especial de la ONU sobre extrema pobreza y derechos humanos, Philip Alston, mantiene como tesis central de su informe que La pobreza es una decisión política; las políticas para salir de la crisis han beneficiado a las clases más altas y perjudicado a las personas más excluidas. Acusa a la clase política de fallar 
que poner en duda la obligatoriedad de la norma nos aboca a una situación de anomia y de caos social; por ello, el excluido de la participación social sí está obligado por las normas; su situación, en todo caso, deberá ser tenida en cuenta a la hora de individualizar las penas, como atenuante. Pero si es el propio Estado, en el marco de un régimen segregacionista, el que rompe la lógica del pacto de derechos-deberes, exigiendo a la ciudadanía deberes, sin protección de derechos, la resolución sobre la legitimidad de las normas y de las penas es más compleja.

6. Entre nosotros, Cigüela Sola ha hecho un esfuerzo muy interesante por construir una crítica sobre la legitimidad del castigo del excluido social ${ }^{78}$. Sola propone que la capacidad de castigo de un Estado -el "ius punendi" - es ilegítimo si está orientado a regular actuaciones que una persona hace como consecuencia de su falta de reconocimiento e integración social ${ }^{79}$; esto es, como consecuencia del desamparo al que ha sido abocado por el Estado y su institucionalidad. Nos moveríamos en el umbral de actuación de un Estado que humilla. Las causas de ilegitimidad de la pena por parte de un Estado humillante dependerán, en su intensidad, de dos variables interdependien-

y no otorgar atención a las clases más vulnerables. Un país, España, en el que los derechos económicos y sociales se toman raramente en serio; donde el 26,1\% de la población en España, y el 29,5\% de los niños, se encontraban en riesgo de pobreza o exclusión social; donde más de la mitad de la población tuvo dificultades para llegar a fin de mes y el 5,4\% experimentó privación material severa; donde sucesivos Gobiernos han decidido intencionadamente bajar las tasas impositivas y ayudar a las compañías, no perseguir la evasión fiscal, manteniendo niveles de protección social muy bajos. Según Alston, en España la pobreza y la precariedad están integradas en el sistema. Considera que es necesario todo un pacto distributivo, con un sistema fiscal más progresivo y con niveles más altos de impuestos para las clases más pudientes. Las políticas de vivienda son desastrosas, con un parque de viviendo pública mínimo en comparación con otros países, con una cifra de desahucios alarmante y un mercado laboral que no funciona nada bien para las personas más precarias. Ello se complementa con un sistema de políticas mínimas de inserción muy precario. https://elpais.com/sociedad/2020/02/07/ actualidad/1581076697_951659.html?fbclid=IwAR2ycnfQCmPnMKOfgnDL41Caz0v_8loQIPyN3_ UJt6_ApocPsRXiGJsmLCk (consultado 8 de febrero de 2020).

78 Crimen y castigo del excluido social. Sobre la ilegitimidad politica de la pena, op. cit.; "Aproximación a una dogmática de la exclusión social: de la imputabilidad a la individualización", Revista de Derecho Penal y Criminológica, núm. 17, 2017, pp. 13-46; “Derecho penal y exclusión social: la legitimidad del castigo del excluido", Isonomía, núm. 43, 2015, pp. 129-150; "El ciudadano y el excluido frente al derecho penal", InDret, 2017, pp. 1-35.

79 Crimen y castigo del excluido social. Sobre la ilegitimidad política de la pena, cit., pp. 260-270. 
tes y conectadas: i) la gravedad y las formas que adquiere la injusticia padecida por la ciudadanía, pudiendo evidenciar la existencia de una íntima conexión, una suerte de causalidad objetiva, entre el delito producido por la persona excluida y el desamparo negligente y meditado producido por un Estado humillante, mediante el análisis de las estructuras de la institucionalidad estatal que producen exclusión; ii) la gravedad de la infracción del delincuente y el daño que produce sobre el bien común y el conjunto de la ciudadanía.

La inexigibilidad hipotética de una pena es debido no a lo que el excluido pueda hacer o dejar de hacer; sino a todo aquello que es debido a su falta de reconocimiento, al ejercicio de desamparo al que ha sido abocado por Estado, quien es co-productor de la situación de exclusión generada.

Para abordar este marco de ilegitimidad de la pena y poder elaborar una dogmática de la exclusión que permita transitar hacia escenarios de inimputabilidad del excluido por falta de legitimidad de un Estado (humillante), diseña un arco de posibilidades que dan muestra del abandono de la responsabilidad por parte del Estado para con su ciudadanía más necesitante ${ }^{80}$ :

i) La hipocresía del Estado, lo que implica que personas y grupos se auto-provean para satisfacer sus propias necesidades y derechos, provisión que tendría que haber sido ofertada por y desde el Estado. Ello se traduce en una suerte de autogestión precaria por parte de la persona excluida, proyectada a la búsqueda de salidas de necesidad generadas por contextos de exclusión -la autarquía personal como condición de posibilidad para no resultar dependiente-. Todo ello macera el nicho de cultivo propicio para la comisión de delitos. No hay una relación de causalidad entre la hipocresía del Estado y la producción de exclusión; pero su hipocresía es un presupuesto que facilita e influye en la producción sistemática de exclusión;

ii) La complicidad del Estado en la generación de situaciones estructurales de exclusión. Ésta constituye un complemento de la anterior perspectiva, pero desde una dimensión más holística, como es la del sistemático desmontaje del Estado social;

iii) La selectividad del Estado en la promoción de la ayuda y el castigo -la doble moral estatal-, reaccionando de manera mucho más lesiva y represora respecto a los sectores más frágiles y excluidos, que respecto a otros sectores con gran capacidad de influencia en el Estado y su insti-

80 Ibidem, pp. 224-225; 266-267. 
tucionalidad ${ }^{81}$. En estos supuestos se procede a través de una contradicción en la propia praxis política del Estado que incluye selectivamente a las personas más excluidas para castigar más represivamente ${ }^{82}$;

iv) La persecución de personas y sectores -minorías raciales, sexuales, étnicas, nacionales, religiosas, defensores de derechos humanos etc.- a través de actos, políticas y normativas densamente discriminatorias en su manera de enunciación y aplicación, siendo la propia institucionalidad del Estado (Administración, judicatura) la que coadyuva a la producción de un delito. El tratamiento represivo, discriminatorio y vejatorio de pueblos indígenas, mujeres racializadas, minorías negras, personas defensoras de derechos humanos son un ejemplo de ello. Para ello se hace necesario la construcción de tipos penales especiales orientados a criminalizar y perseguir estas actuaciones, con carácter desproporcionado, sin sujeción a Derecho ${ }^{83}$.

Teniendo en cuenta todo lo anterior, Sola establece una distinción necesaria para atenuar o agravar la responsabilidad de la persona excluida, en función de los bienes a los que afecte la conducta (criminal o no) del excluido. Habla de delitos conectados a la idea de dignidad (obligaciones naturales derivados de la dignidad) y los delitos conectados a la idea de ciudadanía (deberes adquiridos) ${ }^{84}$. Si se puede probar la conexión del bien jurídico lesionado con la noción de dignidad, será más sencillo fundamentar la responsabilidad de la persona excluida, dada la cualidad y gravedad de los actos cometidos. Se trata de bienes jurídicos nucleares para el bien común de una sociedad, sin los cuales estamos en la antesala de una sociedad humillante. Por el contra-

81 Expresión palmaria de ello es la asimetría con la que se han perseguido ciertos delitos de corrupción imputables a la clase política, a la banca, a grandes empresarios, a personas influyentes cultural y políticamente, por contraposición a otros sectores.

82 L. WACQUANT, Castigar a los pobres, cit, pp. 15 y ss.; "Deadly Simbiosis: When Ghetto and Prision Meet and Mesh", Punishment E Society, núm. 3, vol. 1, 2001, pp. 95-134; Cárceles de la miseria, cit, pp. 88 y ss.

83 Muchas veces se criminaliza de manera drástica y humillante un acto de protesta o de desobediencia civil, ilegal para las lentes del Estado. En este proceso, sin embargo, el Estado no se cuestiona que él ha sido -con su praxis- el responsable y co-productor de ciertas reacciones que tratan de remover la coyuntura de exclusión a la que muchos sectores se han visto abocados. De nuevo la complicidad del Estado, en cuanto productor de exclusión, es importante para pensar la ilicitud de las reacciones, el ámbito de exigencia de las responsabilidades, la definición dogmática de los delitos y la canalización de las penas.

84 J. CIGÜELA SOLA, Crimen y castigo del excluido social, cit., pp. 197-198; también J M ${ }^{a}$ SILVA SÁNCHEZ, Malum passionis. Mitigar el dolor del Derecho penal, Atelier, Barcelona, 2018, pp. 67-112 
rio, cuanto más conectado esté el delito con la noción de ciudadanía política más difícil será justificar dicha responsabilidad del excluido, más fácil imputar la misma al Estado y, por tanto, deslegitimar sus políticas de castigo.

Sola establece una distinción interesante, pero polémica, entre bienes primarios y secundarios cuando se trata de personas en riesgo de exclusión. Entiende por primarios aquellos que están más vinculados a la vida, integridad física y psíquica. Entiende por secundarios, otros, aquellos que tienen que ver con resistencia, delitos patrimoniales, en definitiva, bienes de menor importancia social. Sin embargo, en la comprensión de SOLA hay una consideración generacional, dicotomizada y no interdependiente de los derechos y los bienes jurídicos. La doctrina de derechos humanos ha venido estableciendo una suerte de interdependencia entre derechos civiles y políticos, sociales y culturales; no pudiéndose dar disección, ni fractura entre ellos, pues asistiríamos a una dislocación sistémica de la Dogmática los derechos. La distinción tan discernidamente analítica que realiza el autor entre bienes primarios y secundarios, aunque es pedagógica, no es muy plausible para la comprensión del imaginario criminal y para la explicación de la política criminal en el supuesto que venimos abordando: la exclusión social grave. Uno roba pues sus condiciones de vida son enormemente precarias y esa precariedad se enreda con otras condiciones y factores -múltiples, complejos, interseccionales- que llevan a un delirio criminal que se conecta con una praxis selectiva, progresiva, sedimentada y sistemática de abandono del Estado a su ciudadanía excluida. Por tanto, existe una densa interdependencia entre bienes primarios y secundarios, entre derechos, que no permite una clara disección analítica para exonerar de responsabilidad al excluido, o para imputársela por sus actos criminales. Es necesario todavía construir una dogmática de la exclusión más compleja que dé medida de la multiplicidad de factores, y de la interseccionalidad de elementos que se cruzan para generar y producir exclusión con responsabilidad del Estado. El estudio de una dogmática de la prevención criminal, que no vea el delito como un ejercicio de normalidad, sino como un problema social, expresión última de un sustrato más profundo en el que la exclusión tiene un protagonismo fundamental, es algo que está por realizar.

\section{CONCLUSIONES}

1. Hemos intentado reflejar cómo las condiciones con las que se ha venido fraguando la Modernidad tardía, en cuanto productora y reproductora 
de procesos de exclusión, produce cambios paradigmáticos para repensar conceptos tan importantes como los derechos y deberes de la ciudadanía, el control social, la teoría del delito, incluso el concepto mismo de responsabilidad estatal. Una sociedad como la descrita, enfocada hacia políticas criminales de control social, pone su énfasis de actuación en la prevención y gestión de los riesgos, abandonando consideraciones de justicia penal y de derechos necesarias para revitalizar el vínculo comunitario y la confianza ciudadana, así como una concepción participativa de la ciudadanía en la construcción del Derecho y la pena. Con ello se evita la realización de un análisis profundo de las causas estructurales que producen exclusión y, como consecuencia de ello, más desestructuración social.

2. Un Derecho penal que no se adapta a las exigencias de un Estado decente -aquel que no humille y promocione la autarquía y el desarrollo de los individuos y colectivos a través de derechos- no es una política estatal legítima. Un Derecho (penal) no constituido colectivamente -a partir de una concepción que ponga en el centro los deberes de los ciudadanos hacia la comunidad y de ésta hacia la ciudadanía a través del Estado- pierde legitimidad para poder regular y castigar ciertos delitos procedentes de procesos de exclusión en los que el Estado ha funcionado como co-productor y reproductor de tales condiciones.

3. Constituye un grave problema moral imponer castigos en contextos en los que el Estado llama a las personas delincuentes a rendir cuentas cuando, por su deriva humillante, no está en condiciones de hacerlo. Si no se dan las precondiciones sociales y políticas necesarias para que el Derecho penal hable en nombre y representación de una comunidad a la que ha desamparado y excluido; cuando el Derecho habla por medio y a través de un lenguaje que la ciudadanía (excluida) no puede comprender ni asumir como propio, debido al carácter excluyente del mismo y debido a la fractura del vínculo comunitario que se ha venido produciendo en la construcción del Derecho; cuando se diseñan modelos de justicia penal basados en la imposición sobre personas delincuentes en régimen de exclusión de un tratamiento abusivo respecto a otras personas y otras situaciones análogas, desvinculando a estas de la comunidad y sus procesos, fracturando la posibilidad de rehabilitación e inclusión social con derechos, nos asomamos a la falta de legitimidad del Estado para castigar y reclamar los deberes que incluye el vínculo social de la ciudadanía. 
4. Resulta fundamental una transformación radical del pensamiento jurídico que permita repensar otras formas de penalidad centradas en una consideración amplia de los derechos y deberes de la ciudadanía en prisión. Para ello es imprescindible pensar los modos y las maneras de introducir prácticas de Justicia Transicional complejas que permitan dar nueva orientación a dimensiones tan fundamentales como: las condiciones de rehabilitación e inclusión social; la reformulación de un nuevo imaginario para entender la sanción punitiva; el replanteamiento de la función de las prisiones en cuanto instrumento principal de rehabilitación, mecanismo imprescindible para la retribución social; la reformulación de la relación víctima-victimario como condición de posibilidad para la reconstrucción del vínculo comunitario, abandonando una consideración predominante de la víctima como el gran elemento a considerar a la hora de determinar el castigo; despolitizar y evitar la presión populista en la determinación de la pena y en la consideración del proceso rehabilitador de las personas delincuentes, entre otras.

Asier Martínez de BRINGAS Universidad de Deusto, Facultad de Derecho Avenida de las Universidades 24 48007 Bilbao e-mail:asier.martinezb@deusto.es 